\title{
Selection of Fish Raw Material Suppliers by Integrating ANP and Topsis Methods in CV. Riki Utama Mandiri
}

\section{Pemilihan Supplier Bahan Baku Ikan dengan Mengintegrasikan Metode ANP dan Topsis di CV. Riki Utama Mandiri}

\author{
Aula Fajar Iman Sakti ${ }^{1}$, Wiwik Sulistiyowati ${ }^{2}$ \\ \{aulafajarimansakti@gmail.com ${ }^{1}$,wiwik@umsida.ac.id ${ }^{2}$ \} \\ Program Studi Teknik Industri, Fakultas Sains dan Teknologi, Universitas Muhammadiyah Sidoarjo
}

\begin{abstract}
CV. Riki Utama Mandiri is a company in distributing an economic fish frozen product. This company distributed any kind of retail and wholesaler, both domestic and export. They distributing many frozen fish products variant such as Patin Fillet and Shark Fin. The all raw materials of those frozen seafood was obtained by three different suppliers. The common problems found in CV. Riki Utama Mandiri mostly about raw patin fish supplier which often committed delivery delays. The purpose of this research is to fixing the supply chain management in deciding the more accurate selections of raw materials supplier. To overcome the common problems that happen. Analytical network process (ANP) will simplify the criteria weight values and sub criteria of each supplier. Meanwhile, technique for others reference by similarity to ideal solution (TOPSIS) method is used for giving a rank order of the alternative supplier. This research is expected for being a consideration for the company in obtaining a good and more effective kind of raw supplier. We also expecting the company for tighten supplier selection more effective way so that it can fullfilled the existing standard. Also to overcome the common problems such as delivery delays, competing raw materials with uncertain quality, and difficulty in sort out the raw materials due to size issues.
\end{abstract}

Keywords - Analytic Network Process (ANP); TOPSIS; Supplier Selection

\begin{abstract}
Abstrak. CV. Riki Utama Mandiri ini bergerak pada bidang distributor ikan frozen murah. Perusahaan ini melayani distribusi semua lapisan pasar retail dan grosir, domestik maupun export. Produk yang distirbusikan meliputi banyak varian frozen ikan seperti fillet ikan patin dan juga sirip hiu. Seтua bahan baku dari produk seafood frozen ini diperoleh dari supplier yang diambil dari tiga supplier yang berbeda. Adapun permasalahan yang sering ditemui pada CV. Riki Utama Mandiri terutama pada bagian supplier bahan baku ikan patin khususnya. Adalah sering terjadinya keterlambatan pengiriman. Tujuan dari penelitian ini yaitu untuk memperbaiki supply chain management dalam menentukan pilhan yang lebih akurat terhadap supplier-supplier bahan baku, guna untuk menanggulangi permasalahan-permasalhan yang ada. Adapun dengan metode analytical network process (ANP) akan mempermudah penyeleksian data pemasok untuk memperoleh nilai bobot kriteria dan sub kriteria pada masing-masing supplier. Sedangkan metode technique for others reference by similarity to ideal solution (TOPSIS) dipergunakan untuk memberikan urutan rangking pada alternatif supplier. Dari penelitian ini diharapkan dapat menjadi bahan pertimbangan perusahaan untuk mendapatkan supplier bahan baku yang tepat dan efektif. Dan perusahaan agar lebih memperketat penyeleksian supplier dengan lebih efektif yang memenuhi standart yang ada. Agar dapat mengurangi kendala-kendala yang ada terdahulu seperti keterlambatan pengiriman, persaingan dalam mendapatkan bahan baku kualitas bahan baku yang tidak menentu dan sulitnya memilah bahan baku karena perbedaan besar dan kecilnya.
\end{abstract}

Kata Kunci - Analytic Network Process (ANP); TOPSIS; Pemilihan Supplier

\section{Pendahuluan}

Supplier adalah peranan yang sangat penting dalam perputaran industri manufaktur maupun jasa. Tugas supplier sangatlah penting yang meliputi tiga tugas pokok yaitu sebagai pihak yang memastikan ketersediaan produk, memastikan bahan baku yang akan dipasok adalah kualitas terbaik, mengatur proses penyimpanan bahan baku sebelum dikirim ke perusahaan pemesan, dan mengatur pengiriman bahan baku [1]. Salah satu perusahan yang bergerak pada bidang pemasok barang adalah CV. Riki Utama Mandiri Seafood.

Adapun permasalahan dari CV. Riki Utama Mandiri adalah adanya keterlambatan pengiriman bahan baku dari para supplier dan tidak mampu memenuhi kebutuhan bahan baku dari CV. Riki Utama Mandiri. Dikarenakan itu diperlukannya pemilihian supplier terbaik dari beberapa supplier agar mampu menanggulangi keterlambatan yang ada. Oleh karena itu dilakukan penelitian ini dengan menggunakan dua metode perhitungan yaitu analytical network process (ANP) dan technique for others reference by similarity to ideal solution (TOPSIS). Pengunaan kedua metode tersebut disesuaikan dengan fungsi masing-masing seperti analytical network process (ANP) digunakan sebagai penyeleksi data pemasok untuk memperoleh nilai bobot kriteria dan sub kriteria pada pemilihan supplier [2]. Dan 
technique for others reference by similarity to ideal solution (TOPSIS) digunakan untuk memberikan urutan rangking pada alternarif supplier [3].

Penelitian ini bertujuan untuk mengetahui supplier terbaik untuk menjadi mitra kerja secara kontinu guna menangulangi keterlambatan atau memperbaiki efisiensi waktu. Dan mengetahui kriteria apa saja yang diperlukan untuk menilai supplier agar dapat secara tepat dalam memilih supplier terbaik untuk diajak bermitra dengan CV. Riki Utama Mandiri. Analytical network process (ANP) sendiri digunakan untuk memberi bobot dengan kriteria dan subkriteria yang ada sedangkan technique for others reference by similarity to ideal solution (TOPSIS) diperuntukan setelah perhitungan Analytical network process (ANP) selesai sebagai pemberi rengking pada supplier dari nilai preferensi [6][7].

\section{METODE}

Menjelaskan tentang kegiatan selama proses penelitian dari mulai studi pustaka, studi lapangan, pengumpulan data, dan analisa data sampai dengan akhir proses penelitian. Berikut ini merupakan gambar dari flowchart penelitian yang terlihat pada gambar 1 .

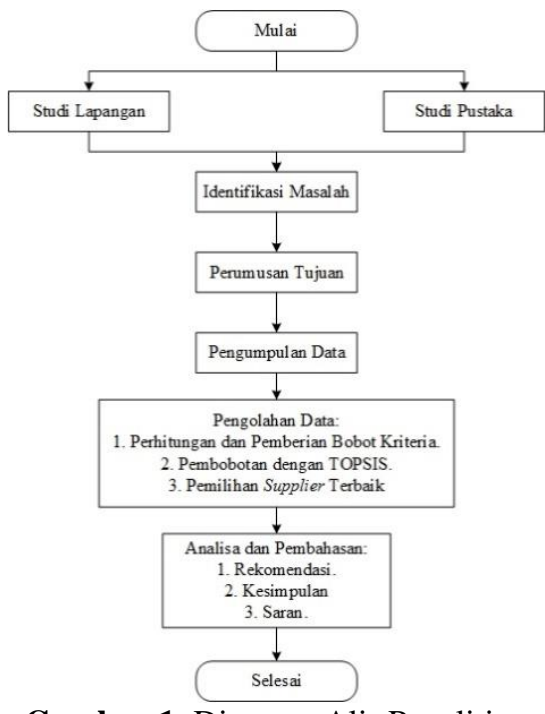

Gambar 1. Diagram Alir Penelitian

\section{A. Pemilihan supplier}

Memilih supplier merupakan kegiatan strategi dan wajib bagi perusahaan. Pemilihan supplier sangat utama apa bila supplier tersebut adalah pemasok bahan baku utama, kritis, dan digunakan dengan jangka panjang. Salah satu hal penting dari pemilihan supplier adalah kriteria pemilihan [8]. Kriteria yang digunakan harus sesuai dengan strategi supply chain dan karakter dari bahan baku yang akan di pasok. Secara umum perusahaan dapat menggunakan kriteriakriteria dasar seperti kualitas bahan baku, harga, dan ketepatan waktu pengiriman. Kriteria pemilihan supplier diambil dari proses pertimbangan kriteria finansial dan non finansial dikarenakan kriteria non finansial sangat berpengaruh pada penilaian dan sebagai acuan utama pada penilaian kinerja suatu supplier [13]

\section{B. Analytical network process (anp)}

Analytical network process atau ANP adalah metode yang dijadikan alat pengolahan data seleksi supplier untuk memberikan nilai bobot kriteria kepada tiap-tiap supplier. Metode ANP merupakan metode yang harus mengunakan data asli yang berasal dari variabel-variabel penilaian informan dari hasil lapangan langsung [4]. Langkah-langkah pada metode ANP adalah sebagai berikut:

1. Langkah 1

Konstruksi model dan membuat struktur masalah. Konstruksi model diambil dari permasalahan yang ada.

Sehingga memerlukan deskripsi masalah secara jelas dan dibentuk pada suatu jaringan [9].

2. Langkah 2

Menujukan keterkaitan dengan menggunakan matriks perbandingan berpasangan. Perbandingan berpasangan dapat dilakukan dengan melakukan perbandingan tingkat kepentingan elemen terhadap setiap keriteria kontrolnya. Dengan penilaian skala pada tabel 1 berikut :

Tabel 1. Pedoman Pemberian Nilai Perbandingan Berpasangan

\begin{tabular}{ccc}
\hline Kepentingan & Definisi & Penjelasan \\
\hline 1 & Kedua kriteria sama penting & $\begin{array}{c}\text { Kedua elemen memiliki [engaruh yang } \\
\text { sama }\end{array}$ \\
\hline
\end{tabular}


Procedia of Engineering and Life Science Vol.1 No. 2 June 2021

Seminar Nasional \& Call for Paper Fakultas Sains dan Teknologi (SENASAINS 2nd)

Universitas Muhammadiyah Sidoarjo

\begin{tabular}{ccc}
\hline 3 & $\begin{array}{c}\text { Kriteria yang satu sedikit lebih } \\
\text { penting }\end{array}$ & Sedikit lebih memihak pada satu elemen \\
\hline 5 & $\begin{array}{c}\text { Kriteria yang satu lebih penting } \\
\text { dari pada yang lainnya }\end{array}$ & $\begin{array}{c}\text { Memihak satu elemen dibandingkan } \\
\text { pasangannya }\end{array}$ \\
\hline 7 & $\begin{array}{c}\text { Kriteria yang satu jelas sangat } \\
\text { penting dari pada yang lainnya }\end{array}$ & Satu elemen sangat disukai \\
\hline 9 & $\begin{array}{c}\text { Kriteria yang satu mutlak sangat } \\
\text { penting dari pada yang lainnya }\end{array}$ & Satu elemen sangat disukai \\
\hline $\begin{array}{c}\text { Nilai tengah daintara dua } \\
\text { pertimbangan yang berdekatan }\end{array}$ & Ketika diperlukan kompromi \\
\hline
\end{tabular}

3. Langkah 3

Perhitungan bobot elemen yaitu menentukan nilai eigen (bobot) dari matriks. Perhitungan bobot elemen adalah dengan menjumlahkan nilai dari setiap kolom lalu membagi setiap nilai sel kolom dengan total kolom dan menjumlahkan nilai-nilai dari setiap baris lalu dibagi $n$. Seperti pada rumus berikut:

4. Langkah 4

Rasio konsentrasi merupakan rasio penentu konsisten atau tidaknya penilaian yang meliputi CI dan CR.

\section{Technique for others reference by similarity to ideal solution (topsis)}

Metode TOPSIS atau technique for others reference by similarity to ideal solution ini mempertimbangkan kedua jarak yatu dari solusi ideal positif dan solusi ideal negatif dengan kelebihan metode TOPSIS ini yang mengambil kedekatan relatif terhadap solusi ideal positif [10]. Berdasarkan pembandingan terhadap jarak relatifnya dan susunan prioritas yang bisa dicapai alternatif [5]. Langkah-langkah penyelesaian masalah dengan metode TOPSIS adalah seperti berikut:

1. Membuat matriks keputusan yang ternomalisasi (r).

TOPSIS adalah metode yang membutuhkan tingkatan kerja setiap alternatif $\left(A_{i}\right)$ pada setiap kriteria $\left(C_{j}\right)$ yang ternomalisasi. Dapat dihitung dengan rumus seperti berikut:

Keterangan:

$$
r_{i j}=\frac{X_{i j}}{\sqrt{\sum_{i=1}^{m} X_{i j}^{2}}}, i=1,2, \ldots, m ; j=1,2, \ldots, n
$$

$\mathrm{r}_{\mathrm{ij}} \quad$ Matriks normalized

$\mathrm{x}_{\mathrm{ij}} \quad=$ Matriks keputusan

2. Membuat matriks keputusan yang ternomalisasi terbobot (y).

Matriks ternormalisasi terbobot dimana $W_{j}$ merupakan bobot dari kriteria ke-j. Dapat dihitung dengan rumus sebagai berikut:

$$
y_{i j}=W_{j} r_{i j}
$$

3. Menentukan Matriks Solusi ideal positif dan negatif $\left(\mathrm{A}^{+}\right)$dan $\left(\mathrm{A}^{-}\right)$.

4. Menentukan jarak antar nilai $\left(\mathrm{A}^{+}\right)$dan $\left(\mathrm{A}^{-}\right)$.

$$
\begin{aligned}
& A^{+}=\left(y_{1}^{+}, y_{2}^{+}, \ldots, y_{n}^{+}\right) \\
& A^{-}=\left(y_{1}^{-}, y_{2}^{-}, \ldots, y_{n}^{-}\right)
\end{aligned}
$$

$$
\begin{aligned}
& \mathrm{Di}^{+}=\sqrt{\sum_{\mathrm{i}=1}^{\mathrm{n}}\left(\mathrm{yi}^{+}-\mathrm{y}_{\mathrm{ij}}\right)^{2} ; \mathrm{i}=1,2, \ldots, \mathrm{m}} \\
& \mathrm{Di}^{-}=\sqrt{\sum_{\mathrm{i}=1}^{\mathrm{n}}\left(\mathrm{y}_{\mathrm{ij}}-\mathrm{yi}^{-}\right)^{2} ; \mathrm{i}=1,2, \ldots, \mathrm{m}}
\end{aligned}
$$

Keterangan:

$\mathrm{Di}^{+}=$Solusi ideal positif

$\mathrm{Di}^{-}=$Solusi ideal negatif

5. Menentukan nilai preferensi untuk setiap alternatif.

Untuk menentukan nilai preferensi dimana nilai $\left(V_{i}\right)$ yang lebih besar menunjukan bahwa alternatif $\left(A_{i}\right)$ akan diprioritaskan untuk dipilih. Terlihat pada rumus berikut:

$$
\left(V_{i}\right)=\frac{\mathrm{Di}}{\mathrm{Di}^{-}+\mathrm{Di}^{+}}
$$




\section{HASIL DAN PEMBAHASAN}

\section{A. Menentukan kriteria dan subkriteria}

Metode ANP (analytical network process) sebagai perhitungan awal yaitu penyelekasian dan pengolahan data. Adapun tahapan awal dari ANP adalah penentuan kriteria dan subkriteria sebagai dasar pertimbangan dalam pemilihan supplier. Dari hasil wawancara dan observasi lapangan diperoleh kriteria sebanyak 4 bagian penting dalam pemilihan supplier dan diperoleh subkriteria sebanyak 12 bagian. Terangkum pada tabel 2. berikut ini:

Tabel 2. Kriteria dan Subkriteria

\begin{tabular}{cccc}
\hline Kepentingan & Kriteria & Subkriteria & Kode \\
\cline { 2 - 4 } 1 & \multirow{2}{*}{ Harga } & Kepantasan Harga Dengan Kualitas Ikan & A1 \\
& \multirow{3}{*}{ Kualitas } & Kemampuan Memberikan Potongan & A2 \\
\hline \multirow{2}{*}{2} & & Kesesuaian Ikan Dengan Spesifikasi & B1 \\
& & Penyediaan Ikan Tanpa Cacat & B2 \\
& \multirow{3}{*}{ Layanan } & Kemampuan Memberikan Kulitas & B3 \\
\hline \multirow{2}{*}{3} & & Kemudahan Untuk Dihubungi & C1 \\
& & Kecepatan Dalam Menangapin Permintan & C2 \\
& \multirow{3}{*}{ Ketepatan } & Cepat Dalam Memperbaiki Keluhan Pelanggan & C4 \\
\hline & & Tepat Mengirim Ikan yang Sesuai Pesanan & D1 \\
& & Tepat Waktu Dalam Pengiriman & D2 \\
& & Tepat Dalam Penanganan & D3 \\
\hline
\end{tabular}

Pada penentuan hubungan kriteria dan subkriteria ini ada dua macam hubungan yaitu inner dependence dan outer dependence. Inner dependence adalah hubungan keterkaitan antar subkriteria di dalam suatu kriteria. Sedangkan outer dependence menujukan hubungan keterkaitan antara kriteria maupun antara kriteria dan alternatif [11]. Dapat terlihat gambar lebih jelasnya pada gambar 2 yang menunjukan susunan model ANP pada perhitungan ini dengan bantuan software super decision [12].

\section{B. Pembobotan kriteria}

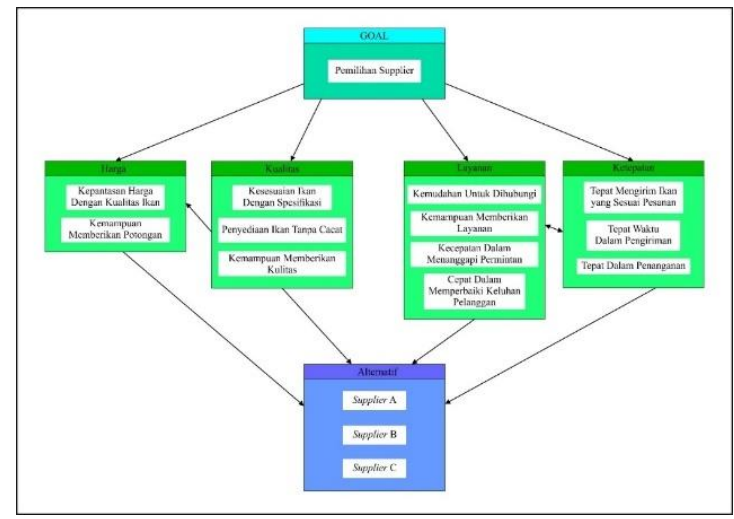

Gambar 2. Model ANP Pemilihan Supplier

Perbandingan berpasangan ini akan selalu mengunakan skala 1-9 yang nantinya akan dipergunakan untuk membuat nilai pada kuisioner. Ketika responden pada kuisioner adalah lebih dari satu, maka akan digunakan perhitungan rata-rata mengunakan deret geometrik untuk mendapat nilai kepentingan relatif. Dengan nilai kepentingan relatif inilah yang nantinya akan diolah pada software super decision. Berikut adalah tabel 3 yang berisi skala intensitas kepentingan:

Tabel 3. Skala Intensitas Kepentingan

\begin{tabular}{cc}
\hline Intensitas Kepentingan & Keterangan \\
\hline 1 & Kedua elemen sama pentingnya \\
\cline { 2 - 2 } 5 & $\begin{array}{c}\text { Elemen yang satu sedikit lebih penting dibanding elemen yang } \\
\text { lainnya }\end{array}$ \\
\cline { 2 - 2 } 7 & Elemen yang satu lebih penting dibanding elemen lainnya \\
\cline { 2 - 2 } & Satu elemen jelas lebih mutlak pentingnya dibandingkan elemen \\
lainnya
\end{tabular}


Procedia of Engineering and Life Science Vol.1 No. 2 June 2021

Seminar Nasional \& Call for Paper Fakultas Sains dan Teknologi (SENASAINS $2^{\text {nd }}$ )

Universitas Muhammadiyah Sidoarjo

Satu elemen mutlak daripada elemen yang lainnya

Nilai-nilai diantara dua nilai pertimbangan yang berdekatan

\section{Hasil pembobotan kriteria}

Langkah berikutnya adalah proses pencarian CR (Consistensy Ratio) yaitu hasil dari perhitungan uji konsistensi yang dipergunakan untuk mengetahui kekonsistenan hasil data yang telah diambil [14]. Maka pembahasan selanjutnya adalah tentang rentetan proses pencarian CR (Consistensy Ratio) dari hasil kuisioner dengan menggunakan microsoft excel. Bobot kriteria diperoleh terlihat pada tabel 4 berikut :

Tabel 4. Bobot Kriteria

\begin{tabular}{c|c}
\hline Kriteria & Bobot \\
\hline Harga & 0.275 \\
Kualitas & 0.262 \\
Layanan & 0.135 \\
Ketepatan & 0.329 \\
\hline
\end{tabular}

Menghitung konsistensi ratio (CR) adalah dengan menghitung nilai matriks B yaitu dengan cara perkalian matriks awal (A) dengan bobot kriteria. Dengan hasil pada tabel 5 sebagai berikut:

Tabel 5. Perhitungan Akhir Nilai Perbandingan Kriteria

\begin{tabular}{|c|c|c|c|c|c|c|c|c|c|}
\hline Kriteria & Harga & Kualitas & Layanan & Ketepatan & $\begin{array}{c}\text { Jumlah } \\
\text { Baris } \\
\text { Matriks } \\
\text { B } \\
\end{array}$ & $\begin{array}{l}\text { Jumlah } \\
\text { Matriks } \\
\text { B/Bobot }\end{array}$ & $\lambda \max$ & $\mathrm{CI}$ & CR \\
\hline Harga & 0.275 & 0.541 & 0.034 & 0.187 & 1.036 & 3.771 & \multirow{5}{*}{4} & \multirow{5}{*}{0} & \multirow{5}{*}{0} \\
\hline Kualitas & 0.191 & 0.262 & 0.553 & 0.101 & 1.107 & 4.230 & & & \\
\hline Layanan & 0.275 & 0.069 & 0.135 & 0.083 & 0.562 & 4.167 & & & \\
\hline Ketepatan & 0.431 & 0.078 & 0.470 & 0.329 & 1.308 & 3.980 & & & \\
\hline \multicolumn{6}{|c|}{ Jumlah } & 16.148 & & & \\
\hline
\end{tabular}

Setelah menemukan hasil dari perhitungan Consistency Index maka dilakukan pehitungan menghitung Consistency Ratio dengan membagi Consistency Index dengan Random Index. Berikut adalah random index yang diperoleh dari eksperimen Oak Ridge National Laboratory dan dilanjutkan oleh Wharton School (Thomas L Satty, 1994). Dengan tabel 6 berikut ini:

Tabel 6. Random Index

\begin{tabular}{ccccccccccc}
\hline $\mathrm{N}$ & 1 & 2 & 3 & 4 & 5 & 6 & 7 & 8 & 9 & 10 \\
\hline $\mathrm{RI}$ & 0 & 0 & 0.58 & 0.9 & 1.12 & 1.24 & 1.32 & 1.41 & 1.45 & 1.49 \\
\hline
\end{tabular}

Semua perhitungan diatas bertujuan untuk mengetahui bahwa hasil dari survei kuisioner merupakan data yang sudah konsisten. Konsisten atau tidaknya data bergantung dari Consistency Ratio (CR) dengan jika nilai CR lebih dari 0.1 maka responden dinyatakan tidak konsisten dalam memberikan nilai pada kuisioner oleh karena itu data tersebut tidak dapat digunakan pada perhitungan selanjutnya. Berikut adalah hasil perhitungan pada software super decision. Terlihat pada gambar 3 berikut ini:

\begin{tabular}{|l|l|l|}
\hline \multicolumn{2}{|c|}{ Normal -1} & \multicolumn{2}{c|}{ Hybrid -1} \\
\cline { 3 - 3 } \multicolumn{2}{|c|}{ Inconsistency: 0.02271 } & 0.24627 \\
\hline Harga & & 0.24627 \\
\hline Ketepatan & & 0.29788 \\
\hline Kualitas & & 0.20959 \\
\hline Layanan & &
\end{tabular}

Gambar 3. Nilai Prioritas dan Inconsistency 


\section{Perhitungan alternatif dengan metode topsis}

Matriks solusi ideal diperoleh dari normalisasi terbobot dan atribut kriteria yaitu cost atau benefit. Solusi ideal terdapat dua yaitu solusi ideal positif dimana nilai maksimal dari normalisasi terbobot pada atribut benefit dan nilai minimal dari atribut cost [15]. Sedangkan solusi ideal negatif adalah kebalikannya. Terlihat pada tabel 7 berikut ini :

Tabel 7. Derajat Kepentingan

\begin{tabular}{ccccc}
\hline & C01 (Cost) & C02 (Benefit) & C03 (Benefit) & C04 (Benefit) \\
\hline $\mathrm{A}+$ & 1.969 & 1.406 & 2.119 & 1.543 \\
\hline $\mathrm{A}-$ & 3.077 & 2.499 & 3.311 & 2.744 \\
\hline
\end{tabular}

Tabel 8. Jarak Antara Alternatif dan Preferensi

\begin{tabular}{cccc}
\hline & D+ & D- & Preferensi \\
\hline A01 & 2.299 & 0.000 & 0.000 \\
\hline A02 & 0.000 & 2.299 & 1.000 \\
\hline A03 & 1.556 & 1.692 & 0.521
\end{tabular}

Dilihat dari tabel preferensi datas didapatkan nilai tertinggi adalah dari alternatif A02 atau Supplier B dengan nilai 1.000. maka alternatif A02 adalah alternatif yang terpilih atau terbaik. Selain itu dalam software super decision alternatif A02 dalam kriteria-kriteria yang ada selalu mendapatkan peringkat tertinggi. Jadi A02 adalah alternatif supplier yang dapat direkomendasikan karena paling memenuhi standart yang ada yaitu harga, kualitas, layanan dan ketepatan.

\section{KESIMPULAN}

Dari perhitungan bab-bab sebelumnya dapat disimpulkan nilai prefrensi tertinggi adalah dari alternatif A02 atau Supplier B dengan nilai 1.000. maka alternatif A02 adalah alternatif yang terpilih atau terbaik. Selain itu dalam software super decision alternatif A02 dalam kriteria-kriteria yang ada selalu mendapatkan peringkat tertinggi. Dalam perhitungan perengkingan supplier dengan mengunakan metode technique for others reference by similarity to ideal solution (TOPSIS) didapatkan nilai tertinggi adalah dari alternatif A02 atau Supplier B dengan nilai 1.000. maka alternatif A02 adalah alternatif yang terpilih atau terbaik. Dari hasil wawancara dan observasi lapangan diperoleh kriteria untuk alat tolak ukur nilai dari pemilihan supplier sebanyak 4 kriteria yaitu harga, kualitas, layanan dan ketepatan. Dari keempat kriteria diatas setiap kriteria memiliki subkriterianya masing-masing yang di total menjadi 12 subkriteria yaitu pada harga terdapat 2 subkriteria, pada kualitas terdapat 3 subkriteria, pada ketepatan terdapat 4 subkriteria dan terakhir pada kriteria ketepatan terdapat 3 subkriteria.

\section{UCAPAN TERIMA KASIH}

Saya ucapkan terima kasih pertama-tama kepada Allah SWT, kepada orang tua saya, dosen pembimbing dan kawan-kawan yang membantu, memberikan motivasi serta dukungan dalam mengerjakan skripsi ini.

\section{REFERENSI}

[1]. Amyriki, Marista dkk. 2016. "Analisis Pemilihan Supplier Gabah dengan Metode Analitycal Network Proces (ANP) Studi Kasus: Gudang Baru Bulog Gunung Gedangan, Mojokerto" Madura: Universitas Trunojoyo Madura Teknologi Industri Pertanian Vol. 9, No. 1. Hal: 1-9.

[2]. Arta, I Kadek Juni dkk. 2016. "Data Mining Rekomendasi Calon Mahasiswa Berprestasi di STMIK Denpasar Menggunakan Metode Technique For Others Reference by Similarity to Ideal Solution" Singaraja: Universitas Pendidikan Ganesha Program Pascasarjana Jurusan Ilmu Komputer Vol. 5, No. 2. Hal: 746-760.

[3]. Ekawati, Ratna dkk. 2018. "Penilaian Performa Supplier Menggunakan Pendekatan Analitycal Network Proces $(A N P)$ " Banten: Universitas Sultan Ageng Tatayasa Fakultas Teknik Jurusan teknik Industri Vol. 3, No. 2. Hal: 152-158.

[4]. Gustian, Sandi dkk. 2018. "Pemilihan Supplier Pada Perusahaan Redbean Berbasis Mobile Mengunakan Hybrid Metode ANP dan Oreste" Bandung: Universitas Sunan Gunug Djati Bandung Fakultas Sains dan Teknologi Jurusan Teknik Informatika Vol. 1, No. 1. Hal: 9-14.

[5]. Lukmandono dkk. 2019. "Pemilihan Supplier Industri Manufaktur dengan Pendekatan AHP dan TOPSIS" Surabaya: Institusi Teknologi Adhi Tama Surabaya Fakultas Teknik Jurusan Teknik Industri Vol. 12, No. 2. Hal: 83-88. 
Procedia of Engineering and Life Science Vol.1 No. 2 June 2021

Seminar Nasional \& Call for Paper Fakultas Sains dan Teknologi (SENASAINS 2nd)

Universitas Muhammadiyah Sidoarjo

[6]. Olanta, Albert Julius dkk. 2019. "Perbandingan Metode ANP dan AHP Dalam Pemilihan Jasa Kurir Logistik Oleh Penjual Gadget Online" Surabaya: Universitas Katolik Widya Mandala Surabaya Fakultas Teknik Jurusan Teknik Industri Vol. 18, No. 2. Hal: 97-101.

[7]. Pakpahan, Ariska Rohanda dkk. 2018. "Komparasi Metode Topsis dan MFEP Dalam Penentuan Pemendang Tender" Surabaya: Sekolah Tinggi Ilmu Komunikasi Fakultas Teknik Jurusan Teknik Informatika Vol. 4, No. 2. Hal: 165-174.

[8]. Pujawan, I Nyoman dan Mahendrawathi. 2017. “Supply Chain Management - Edisi 3” Yogyakarta: Andi Offset.

[9]. Pujawan, I Nyoman dan Mahendrawathi. 2010. “Supply Chain Management - Edisi 2" Surabaya: Institut Teknologi Sepuluh Nopember.

[10]. Pujotomo, Darminto dkk. 2016. "Intergrasi Metode ANP dan TOPSIS Dalam Evaluasi Kinerja Supplier dan Penentuan Prioritas Supplier Bakan Baku Utama Cetak Koran Pada PT Masscom Graphy Semarang" Semarang: Universitas Diponegoro Fakultas Teknik Jurusan Teknik Industri Vol. 11, No. 3. Hal: 151-160.

[11]. Puspitasari, Nia Budi dan Yancadianti, Khairunnisa Hanan. 2016. "Analisa Pemilihan Supplier Ramah Lingkungan Dengan Metode Analitycal Network Proces (ANP) Pada PT Kimia Farma Plant Semarang" Semarang: Universitas Diponegoro Fakultas Teknik Jurusan Teknik Vol. 11, No. 1.

[12]. Rachbini, Widarto J. 2017. “Supply Chain Management dan Kinerja Perusahaan” Jakarta: Universitas Pancasila Jurusan Bisnis dan Bank Vol. 7, No. 1. Hal: 47-56.

[13]. Rimantho, Dino dkk. 2017. "Pemilihan Supplier Rubber Parts Dengan Metode Analitycal Network Proces di PT. XYZ' Jakarta: Universitas Pancasila Fakultas Teknik Jurusan Teknik Industri Vol. 6, No. 7. Hal: 93-103.

[14]. Sulistiyani, Endang dkk. 2017. "Implementasi Metode Analitycal Network Proces (AHP) Sebagi Solusi Alternatif Dalam Pemilihan Supplier Bahan Baku Apel di PT. Mannasatria Kusumawijaya" Surabaya: Universitas Nahdlatul Ulama Surabaya Fakultas Teknik Jurusan Sistem Informasi Vol. 1, No. 2. Hal: 87-101.

[15]. Yusnaeni, Wina dan Ningsih, Rahayu. 2019. “Analisa Perbandingan Metode TOPSIS, SAW dan WP Melalui Iji Sensitifitas Supplier Terbaik” Universitas Bina Sarana Informatika Vol. 6, No. 1. Hal: 9-17. 